\title{
Optimization of blend parameters for the fabrication of polycaprolactone-silicon based ormoglass nanofibers by electrospinning
}

Nadège Sachot ${ }^{1,2}$, Oscar Castano ${ }^{1,2,3,4, *}$, Josep A. Planell ${ }^{1,2,3}$ and Elisabeth Engel ${ }^{1,2,3}$

${ }^{1}$ Biomaterials for Regenerative Therapies, Institute for Bioengineering of Catalonia (IBEC), Baldiri Reixac 15-21, 08028 Barcelona, Spain

${ }^{2}$ CIBER de Bioingenieria, Biomateriales y Nanomedicina (CIBER-BBN), Baldiri Reixac 1521, 08028 Barcelona, Spain

${ }^{3}$ Materials Science and Metallurgical Engineering, Universitat Politècnica de Catalunya, 08028, Barcelona, Spain

${ }^{4}$ Materials Science and Metallurgical Engineering, Universitat de Barcelona, 08028, Barcelona, Spain

*corresponding author: ocastano@ibecbarcelona.eu, +34 93402021

\begin{abstract}
Electrospinning is a method that can be used to efficiently produce scaffolds that mimic the fibrous structure of natural tissue, such as muscle structures or the extracellular matrix of bone. The technique is often used as a way of depositing composites (organic/inorganic materials) to obtain bioactive nanofibers which have the requisite mechanical properties for use in tissue engineering. However, many factors can influence the formation and collection of fibers, including experimental variables such as the parameters of the solution of the electrospun slurry. In this study, we assessed the influence of the polymer concentration, glass content and glass hydrolysis level on the morphology and thickness of fibers produced by electrospinning for a PCL-(Si-Ca-P $\left.{ }_{2}\right)$ bioactive ormoglass - organically modified glass - blend. Based on previous assays, this combination of materials shows good angiogenic and osteogenic properties, which gives it great potential for use in tissue engineering. The results of our study
\end{abstract}


showed that blend preparation directly affected the features of the resulting fibers, and when the parameters of the blend are precisely controlled, fibers with a regular diameter could be produced fairly easily when 2,2,2-trifluoroethanol was used as a solvent instead of tetrahydrofuran. The diameter of the homogeneous fibers ranged from $360 \mathrm{~nm}$ to $620 \mathrm{~nm}$ depending on the experimental conditions used. This demonstrates that experimental optimization of the electrospinning process is crucial in order to obtain a deposit of hybrid nanofibers with a regular shape.

Keywords: Si-based glasses; ormoglass; electrospinning; hybrid materials; bioactivity; angiogenesis

\section{Introduction}

In the last decade, the use of nanotechnology and nanomaterials in numerous material applications has greatly increased. Nanostructured materials are especially essential in tissue engineering, as cells regulate their behavior depending on the physical signals they receive at this scale, such as the nanotopography, nano-roughness and nanosized structure, etc ${ }^{1-3}$. The physical environment, along with soluble cues, is a key variable affecting the success of a scaffold implantation and subsequent regeneration of the tissue. The porosity and elasticity of a substrate, as well as its architecture, can influence biological responses.

Fibrous structures obtained by electrospinning are currently a very popular method to produce temporary nanoscale structures, either polymeric or composite, for cellular adhesion, proliferation and differentiation ${ }^{4-6}$. An advantage of the electrospinning method is that is allows the design of biomimetic matrices that are organized in a similar way to the collagenous 
fibrils of the natural bone extracellular matrix ${ }^{6-8}$. The technique has a low cost-effective ratio, is very versatile, and enables the fabrication of fibers with diameters ranging from the nano- to the microscale ${ }^{8,9}$. Moreover, this process does not involve sophisticated equipment.

The setup consists of a syringe pump, a voltage source and a metallic collector. The principles behind the formation of fibers rely on the competition between the electrostatic forces formed on the surface of a polymeric solution when it is subjected to a high voltage, and its surface tension. When the voltage is applied to the liquid drop (gradually appearing at the syringe tip due to the dispensing of the polymeric solution), the fluid charges, and as a result, repulsive electrostatic forces appear. The liquid, however, maintains its confinement (drop shape) thanks to its surface tension, but only up to a certain voltage. If the intensity of the voltage is sufficiently increased up to a critical point, repulsive forces overcome the surface tension and a liquid jet rises from the drop. At this moment, a Taylor cone forms ${ }^{10}$. The further the jet travels from the drop, the more elongated and thinner it becomes, because of its instability. In fact, it starts to whip, then bend and stretch ${ }^{11}$. During this whipping process, the solvent evaporates and the jet solidifies. The resulting fibers are collected on a grounded metallic support either as non-woven or woven mats, using a fixed or a rotary collector respectively 12,13 .

To determine the final features of electrospun fibers, several variables can be manipulated: the intrinsic properties of the solution (viscosity, solvent dielectric constant), ambient factors (humidity, room temperature), and setup conditions (liquid dispensing rate, voltage applied, tip-to-collector distance) ${ }^{14,15}$.

Polycaprolactone (PCL) is already a well-known synthetic polymer in bone tissue engineering due to its biodegradable and biocompatible properties ${ }^{16,17}$. It is easy to electrospin ${ }^{18,19}$, but like other synthetic polymers, PCL does not possess intrinsic bioactivity. In a recent study performed by our group, a bioactive phase (Si-Ca-P2 organically modified glass, abbreviated 
to ormoglass) was added to the polymeric solution to provide bioactivity to the resulting electrospun scaffold ${ }^{20}$. The ormoglass was specially selected for its ability to promote osteogenesis and angiogenesis, as well as its integration capability with the host tissue after implantation ${ }^{21-23}$. Our previous study demonstrated that the hybrid organic-inorganic fibers induced the formation of blood vessels, as well as osteoblastic differentiation. It was suggested that vascularization was achieved by promoting the secretion of the VEGF growth factor by modulating the release of calcium ions from the material. Regarding bone formation, it was shown that osteogenesis was promoted by enhancing the activity of the alkaline phosphatase enzyme and the expression of bone proteins, i.e. osteocalcin, osteopontin, collagen I (bone markers indicating differentiation). It also showed that the composition of the ormoglass influenced cellular responses: fibers with the lower silicon content (i.e. the higher calcium content) exhibited the best osteo- and angiogenic properties in comparison to the other two fiber compositions, which had more silicon and less calcium. The calcium release ability (rate and concentration) was suggested to be one of the crucial factors that regulated these processes. This implies that ion release from artificial biomaterials is essential for triggering specific cellular behaviors, and that this PCL/ormoglass combination appears to be a good option for the design of such materials ${ }^{20,24}$.

Despite the remarkable biological performance achieved, it has been noted that depositing the fibers was difficult when using this composite mix with tetrahydrofuran as the solvent. Heterogeneous fibers with beads were obtained in some cases, and only micro-scaled fibers were produced. Given the promising potential of these hybrid templates, being able to produce a clean deposit of fibers has become essential, as has the production of fibers with smaller diameters, in order to better mimic the ECM (nano-sized fibrils) ${ }^{7}$. As such, the aim of this study was to optimize the efficiency of the electrospinning process, enhance the homogeneity 
of the fibers, and to reduce their size by changing different experimental variables such as the solvent, polymer concentration, ormoglass content and ormoglass hydrolysis ratio.

\section{Experimental Section}

\section{Materials}

Polycaprolactone (PCL, Sigma-Aldrich, MW=70-90 kDa) pellets, tetrahydrofuran (THF, Sigma-Aldrich, 99\%), 2,2,2-trifluoroethanol (TFE, Panreac, 99.8\%) were used. In the first part of a preliminary study, PCL solution was prepared by dissolving PCL pellets in THF. In the other parts, PCL was dissolved in TFE.

The ormoglass was prepared by mixing single silicon, calcium and phosphate solutions in the desired molar ratio defined for the study, as previously reported ${ }^{20}$. The silicon precursor was commercially obtained (TEOS, Sigma-Aldrich, 98\%) while the calcium and phosphate precursors were prepared in our laboratory. For this purpose, calcium metallic (Sigma-Aldrich 98\%), 2-methoxyethanol (Sigma-Aldrich, anhydrous, 99.8\%), phosphorus pentoxide (SigmaAldrich, 99.99\%) and absolute ethanol (Panreac, 99.8\%) were used.

\section{Polymer solution and glass precursor mix}

16\% w:w PCL solutions were prepared by dissolving PCL in THF at $60^{\circ} \mathrm{C}$ for the preliminary study. For the second part, PCL solutions were prepared with different polymer percentage (8\%, 10\%, 12\%, 14\%, 15\% and 16\%) but using TFE.

TEOS was used as received from the supplier. Calcium and phosphate precursors were prepared by refluxing calcium metallic in 2-methoxyethanol to produce a calcium-2methoxyethoxide solution $(\mathrm{CaO})$ and phosphorous pentoxide in absolute ethanol to obtain a mono and di-ethylphosphate solution $\left(\mathrm{P}_{2} \mathrm{O}_{5}\right)^{25}$. TEOS, $\mathrm{CaO}$ and $\mathrm{P}_{2} \mathrm{O}_{5}$ precursors were finally 
mixed under nitrogen atmosphere according to the molar ratios targeted for the study (table 1). Thus, an ormoglass precursor mix was obtained.

\section{Polymer/glass blend preparation}

Before being introduced into the polymeric solution, the ormoglass precursor mix was hydrolyzed for 10 seconds. A suspension of ormoglass nanoparticles (Si-Ca-P network) was created by applying the sol-gel method. After hydrolysis, the ormoglass suspension was immediately stirred with the polymer solution for few seconds and then loaded into a syringe for electrospinning. The polymer and ormoglass suspensions were blended according to the experimental conditions summarized in the table 2. Fibers with THF as solvent were produced as a control in order to be compared with the fibers fabricated with the new parameters of blend preparation.

\section{Electrospinning}

Electrospinning setup parameters were constant for the fabrication of all fibers: $12 \mathrm{~cm}$ distance tip-collector, $0.5 \mathrm{ml} / \mathrm{h}$ blend dispensing rate and $7.5 \mathrm{kV}$ voltage applied. Non-woven fibers were collected on a flat metallic support covered with aluminum.

\section{Morphology of fibers}

Scanning electron microscopy (SEM, Quanta Q200, FEI Company) was used to assess the morphology of the fibers. A piece of the fibrous layer deposited on the aluminum was cut and fixed on a conventional metallic support used for SEM observations. The fibers were then sputtered with a thin layer of carbon to improve the conductivity of the samples and ensure good quality observations. 


\section{Diameter measurements of the fibers}

SEM micrographs were opened in ImageJ software and the diameters of fibers were measured using this application ${ }^{26}$. At least 10 measurements were performed to obtain an averaged diameter value for each type of fibers produced.

\section{Results and discussion}

Fibers prepared with THF and different ormoglass compositions: preliminary study (fibers used as control)

Figure 1 shows the morphology of the fibers obtained using THF as solvent and three different ormoglass compositions. Micrographs reveal that the fibers were deposited with imperfections. Fibers with many beads are seen in all three cases, and even fibers with different diameter sizes are observed. This indicates that the electrospinning parameters used were not optimal for the fabrication of homogeneous scaffolds in terms of geometry and thermodynamics of bead formation ${ }^{27}$. The differences in the diameter of the fibers are particularly well represented by the high standard deviation of their diameter average (table 3). The production of fibers with different thicknesses can be explained by the splaying of the primary jet into smaller jets that led to the drying of thinner fibers ${ }^{28}$. Torres-Giner et al., for example, already reported this behavior with a mix of synthetic (PLA) and natural (collagen) polymers ${ }^{29}$. Patlolla et al. also published a study in which bimodal fibers were obtained from a PCL/HA/TCP composite solution ${ }^{30}$. The deposition of multimodal fibers is thus a common problem for electrospun polymer blends.

The use of different ormoglass compositions did not seem to significantly affect the morphology of the fibers, or their average diameter. This suggests that a change in the ormoglass composition is not a critical parameter with regard to the fabrication of the fibers. 
For the other parts of the study, the composition S52 (intermediate) was arbitrarily selected as a fixed parameter, and all fibers produced afterwards to assess the influence of other solution parameters were obtained using this composition.

During the electrospinning process it has been also noted that, even if $\mathrm{Si}-\mathrm{Ca}-\mathrm{P}_{2}$ fibers were properly obtained, fabrication of the fibers using THF as solvent was extremely difficult because the liquid drop at the tip of the syringe solidified rapidly. This prevented the continuous formation of fibers, and regular cleaning steps were necessary to unclog the dispenser (tip). It was hypothesized that this problem may be due to the solvent being used, so THF was replaced by TFE, which was expected to be more suitable for the electrospinning process due to its higher dielectric constant and polarizability (TFE: dielectric constant $\varepsilon=26,14$ at $25^{\circ} \mathrm{C}{ }^{31}$, THF: $\varepsilon=7,58$ at $\left.25^{\circ} \mathrm{C}^{32}\right)$. TFE also possesses a lower vapor pressure $\left(\mathrm{P}_{\mathrm{v}}=9,3 \mathrm{kPa}\right.$ at $\left.25^{\circ} \mathrm{C}^{33}\right)$ and slightly higher boiling temperature $\left(\mathrm{T}_{\mathrm{b}}=74^{\circ} \mathrm{C}\right.$ at $\left.1 \mathrm{~atm}^{31}\right)$ than $\mathrm{THF}\left(\mathrm{P}_{\mathrm{v}}=26.0 \mathrm{kPa}\right.$ at $25^{\circ} \mathrm{C}$ ${ }^{32}, \mathrm{~T}_{\mathrm{b}}=66^{\circ} \mathrm{C}$ at $1 \mathrm{~atm}^{32}$ ); in other words, it is less volatile. In the electrospinning process, the charges in the jet carry the liquid polymer to the collector thanks to the applied high voltage. The evaporation of the solvent has a direct impact on the mechanism of forces transfer through the jet because it affects its viscoelasticity ${ }^{34,35}$. For this reason, a solvent with a lower vapor pressure and higher boiling temperature will exhibit a better mass flow velocity, as it will evaporate slower. Consequently, TFE was selected to improve the processability of the blends due to its intrinsic electrical and thermodynamic properties.

\section{Influence of polymer concentration}

Hybrid fibers with different polymer percentages (w/w) were produced: 8, 10, 12, 14 and 15\% concentration solutions. Submicron scaled fibers were obtained but, in the case of the $12 \%$ solution, they appeared to be slightly less homogenous in diameter than the two other lower concentrations (figure 2). For the higher polymer contents (14 and 15\%), the fiber shape was 
excessively irregular because the viscosity of these blends was too high to produce a welldefined cylindrical shape. In fact, with even higher polymer concentration (16\%), the high viscosity of the solution did not allow the formation of fibers at all. For the $14 \%$ and $15 \%$ solutions, only a few areas on the micrographs were taken into account to measure the diameter of the fibers, because the fibers were not very conspicuous. Measurements revealed that, as for pure PCL fibers (considered here as a control; figure 3), the diameter of the hybrid fibers increased with the concentration of the polymer. This was in agreement with other published

studies ${ }^{36-38}$. In particular, results suggest that the electrospinning process is an efficient method for the production of nanofibers only if the polymer concentrations are within 8 and $10 \% \mathrm{w} / \mathrm{w}$. In addition, fibers produced following these conditions showed more homogeneous fiber size distribution than the rest, as well as being more regular than the hybrid fibers prepared with other polymer concentrations and those prepared with pure PCL solution with the same concentrations. This can be observed in the SEM micrographs and is confirmed by the small standard deviation of the associated diameter measurements.

Finally, it can be noticed that the incorporation of the ormoglass suspension led to fibers with smaller diameters than pure PCL ones. As described, the lower the viscosity (i.e. the lower the polymer concentration) of the electrospun solution, the thinner the diameter of the fibers. The viscosity of the polymeric solution decreased when the less viscous glass suspensions were added, and thus thinner fibers were produced when the blends were electrospun.

\section{Influence of ormoglass content}

According to SEM micrographs, regular fibers were obtained for all ormoglass contents, except for $50 \% \mathrm{v} / \mathrm{v}$ blends (figure 4). Up to the $40 \%$ ratios, fibers with thicknesses around $400 \mathrm{~nm}$ were produced, and no imperfections were observed. In this range of ormoglass:polymer ratio, the electrospinning setup and blend conditions were suitable for the fabrication of an 
appropriate scaffold. However, for the $50 \%$ blends, fibers with larger diameters and more heterogeneous geometries were obtained. In fact, in this case, the content of the ormoglass was too high to achieve a proper PCL-ormoglass blend, because the ormoglass was segregated from the polymer. As a result, the ormoglass dropped from the tip during the electrospinning process as it was not properly or only partially incorporated to the PCL solution, meaning that instead of a synergic PCL-ormoglass blend, only the polymeric phase was electrospun. Therefore it is assumed that the size of the fibers obtained for this ratio is principally determined by the viscosity of the polymeric solution itself. As viscous solutions (i.e polymeric ones) lead to thicker diameter than ones with lower viscosity (in our case, the blends), this would explain why there is a significant difference between the diameter of the fibers with a $40 \%$ of ormoglass content and fibers with a 50\% content.

\section{Influence of hydrolysis level}

In this part of the work, results showed that changes in the hydrolysis ratio led to fibers with different diameters (figure 5). With a hydrolysis ratio higher than 1:5, it was more difficult to obtain thin, homogeneous fibers. In contrast, with a lower hydrolysis ratio, the fibers had diameters below $600 \mathrm{~nm}$ and their morphology was regular. These results suggest that lower hydrolysis ratios enable the production of thinner fibers, though it can be seen that from a ratio of $1: 3$ to a ratio of $1: 10$, the diameters increased. In the sol-gel method, the water introduced to perform the hydrolysis of a glass has a direct influence on the prepared glass precursor suspension, the quantity of water being, in fact, the most important parameter that determines the degree of condensation of the sol ${ }^{39,40}$. As a consequence, ormoglass colloidal suspensions could be obtained as well as gels if the quantity of water added was sufficient ${ }^{41}$. The higher the degree of hydrolysis, the more viscous the glass suspension (or gel). As described previously, the addition of the ormoglass into the PCL solution lowered the viscosity of the 
polymer solution. Thus, by adding more water in the ormoglass precursor mix, the condensation process was more advanced. This implied that a more viscous ormoglass was obtained and, consequently, a more viscous final blend. As a consequence of the increase of the water content, a thickening of the fibers was observed.

\section{Conclusions}

PCL-(Si-Ca-P 2$)$ bioactive ormoglass blends were prepared under different conditions in order to assess the effect of solution preparation (ormoglass hydrolysis, polymer concentration, ormoglass content) on the optimization of the morphology of electrospun fibers and the control of their diameters. Results showed that TFE was a more suitable solvent than THF in term of depositing the fibers efficiently and regularly. Several hybrid blends were appropriate for the production of fibers with homogeneous thicknesses. However, we suggest that to obtain nanosized fibers, polymer solutions with low concentration, blends with ormoglass contents inferior to $40 \%$ (volume), and ormoglass hydrolysis performed with $\mathrm{Si}: \mathrm{H}_{2} \mathrm{O}$ ratios up to 1:5 should be used.

In summary, it has been demonstrated overall that the parameters of the electrospun solution directly influence the features of the fibers. This study therefore provides valuable experimental information for the fabrication of hybrid scaffolds for bone tissue engineering based on polymer-ormoglass fibers.

\section{Acknowledgments}

The authors thank the European Commission (European ERANET project PI11/03030, NANGIOFRAC) and the Spanish Ministry of Economy and Competitiveness-MINECO (Project MAT2011-29778-C02-01) for funding. O.C. thanks the MINECO for the "Ramón y Cajal” and "I3 Programe”. 


\section{References}

1. Lim JY, Donahue HJ. Cell sensing and response to micro- and nanostructured surfaces produced by chemical and topographic patterning. Tissue engineering. 2007;13(8):1879-91.

2. Ross AM, Jiang Z, Bastmeyer M, Lahann J. Physical aspects of cell culture substrates: topography, roughness, and elasticity. Small (Weinheim an der Bergstrasse, Germany). 2012;8(3):336-55.

3. Zhang L, Webster TJ. Nanotechnology and nanomaterials: Promises for improved tissue regeneration. Nano Today. 2009;4(1):66-80.

4. Li W-J, Laurencin CT, Caterson EJ, Tuan RS, Ko FK. Electrospun nanofibrous structure: a novel scaffold for tissue engineering. Journal of biomedical materials research.

2002;60(4):613-21.

5. Huang Z-M, Zhang Y-Z, Kotaki M, Ramakrishna S. A review on polymer nanofibers by electrospinning and their applications in nanocomposites. Composites Science and Technology. 2003;63(15):2223-2253.

6. Jang J-H, Castano O, Kim H-W. Electrospun materials as potential platforms for bone tissue engineering. Advanced drug delivery reviews. 2009;61(12):1065-83.

7. Olszta MJ, Cheng X, Jee SS, Kumar R, Kim Y-Y, Kaufman MJ, Douglas EP, Gower LB. Bone structure and formation: A new perspective. Materials Science and Engineering: R: Reports. 2007;58(3-5):77-116.

8. Ma Z, Kotaki M, Inai R, Ramakrishna S. Potential of nanofiber matrix as tissueengineering scaffolds. Tissue engineering. 2005;11(1-2):101-9.

9. Song J-H, Yoon B-H, Kim H-E, Kim H-W. Bioactive and degradable hybridized nanofibers of gelatin-siloxane for bone regeneration. Journal of biomedical materials research. Part A. 2008;84(4):875-84.

10. Taylor G. Electrically driven jets. Proceedings of the Royal Society of London. Series A, Mathematical and Physical Sciences. 1969;313(1515):453-475.

11. Hohman MM, Shin M, Rutledge G, Brenner MP. Electrospinning and electrically forced jets. I. Stability theory. Physics of Fluids. 2001;13(8):2201-2220.

12. Lu H, Zhang T, Wang XP, Fang QF. Electrospun submicron bioactive glass fibers for bone tissue scaffold. Journal of materials science. Materials in medicine. 2009;20(3):793-8.

13. Li W-J, Mauck RL, Cooper JA, Yuan X, Tuan RS. Engineering controllable anisotropy in electrospun biodegradable nanofibrous scaffolds for musculoskeletal tissue engineering. Journal of Biomechanics. 2007;40(8):1686-1693.

14. Pham QP, Sharma U, Mikos AG. Electrospinning of polymeric nanofibers for tissue engineering applications: a review. Tissue engineering. 2006;12(5):1197-211. 
15. Matabola KP, Moutloali RM. The influence of electrospinning parameters on the morphology and diameter of poly(vinyledene fluoride) nanofibers - effect of sodium chloride. Journal of Materials Science. 2013;48(16):5475-5482.

16. Yoshimoto H, Shin YM, Terai H, Vacanti JP. A biodegradable nanofiber scaffold by electrospinning and its potential for bone tissue engineering. Biomaterials. 2003;24(12):2077-2082.

17. Williams JM, Adewunmi A, Schek RM, Flanagan CL, Krebsbach PH, Feinberg SE, Hollister SJ, Das S. Bone tissue engineering using polycaprolactone scaffolds fabricated via selective laser sintering. Biomaterials. 2005;26(23):4817-27.

18. Thomas V, Jose M V, Chowdhury S, Sullivan JF, Dean DR, Vohra YK. Mechanomorphological studies of aligned nanofibrous scaffolds of polycaprolactone fabricated by electrospinning. Journal of biomaterials science. Polymer edition. 2006;17(9):969-84.

19. Sautter BP. Continuous Polymer Nanofibers Using Electrospinning. University of Illinois, Chicago.; 2005.

20. Castano O, Sachot N, Xuriguera E, Engel E, Planell J a, Park J-H, Jin G-Z, Kim T-H, Kim J-H, Kim H-W. Angiogenesis in bone regeneration: tailored calcium release in hybrid fibrous scaffolds. ACS applied materials \& interfaces. 2014 Apr 22.

21. Oonishi H, Hench LL, Wilson J, Sugihara F, Tsuji E, Matsuura M, Kin S, Yamamoto T, Mizokawa S. Quantitative comparison of bone growth behavior in granules of Bioglass, A-W glass-ceramic, and hydroxyapatite. Journal of Biomedical materials research. 2000;51(1):3746.

22. Gerhardt L-C, Widdows KL, Erol MM, Burch CW, Sanz-Herrera JA, Ochoa I, Stämpfli R, Roqan IS, Gabe S, Ansari T, et al. The pro-angiogenic properties of multi-functional bioactive glass composite scaffolds. Biomaterials. 2011;32(17):4096-108.

23. Blencke B, Brömer H, Deutscher K, Hennig W. Untersuchungen über den histologischen und mechanischen Verbund von glaskeramischen Werkstoffen mit dem Implantatlager. Biomedizinische Technik Band. 1978;23:360-361.

24. Sachot N, Engel E, Castaño O. Hybrid organic-inorganic scaffolding biomaterials for regenerative therapies. Current organic chemistry, accepted.

25. Carta D, Pickup DM, Knowles JC, Smith ME, Newport RJ. Sol-gel synthesis of the P2O5-CaO-Na2O-SiO2 system as a novel bioresorbable glass. Journal of Materials Chemistry. 2005;15(21):2134.

26. Rasband WS. Image J. US National Institute of Health, Bethesda, USA, http://imagej.nih.gov/ij/. 1997:2014.

27. Shui J, Li JCM. Platinum nanowires produced by electrospinning. Nano letters. 2009 [accessed 2014 Aug 6];9(4):1307-14. http://dx.doi.org/10.1021/nl802910h 
28. Reneker DH, Yarin AL, Fong H, Koombhongse S. Bending instability of electrically charged liquid jets of polymer solutions in electrospinning. Journal of Applied Physics. 2000;87:4531-4547.

29. Torres-Giner S, Ocio MJ, Lagaron JM. Development of active antimicrobial fiber based chitosan polysaccharide nanostructures using electrospinning. Engineering in Life Sciences. 2008;8(3):303-314.

30. Patlolla a, Collins G, Arinzeh TL. Solvent-dependent properties of electrospun fibrous composites for bone tissue regeneration. Acta biomaterialia. 2010;6(1):90-101.

31. Mukherjee LM, Grunwald E. Physical properties and hydrogen bonding in the system ethanol-2,2,2-trifluoroethanol. Journal of physical chemistry. 1958;62(10):1311-1314.

32. Coetzee JF, Chang T-H. Purification of solvents for electroanalysis: tetrahydrofuran and dioxane. Pure and Applied Chemistry. 1985;57(4):633-638.

33. Chaudhari SK, Patil KR, Allepfs J, Coronas A. Measurement of the vapor pressure of 2,2,2-trifluoroethanol and tetraethylene glycol dimethyl ether by static method. Fluid phase equilibria. 1995;108:159-65.

34. Reneker DH, Chun I. Nanometre diameter fibres of polymer, produced by electrospinning. Nanotechnology. 1996;7(3):216-223.

35. Megelski S, Stephens JS, Chase DB, Rabolt JF. Micro- and Nanostructured Surface Morphology on Electrospun Polymer Fibers. Macromolecules. 2002;35(22):8456-8466.

36. Deitzel J., Kleinmeyer J, Harris D, Beck Tan N. The effect of processing variables on the morphology of electrospun nanofibers and textiles. Polymer. 2001;42(1):261-272.

37. Demir MM, Yilgor I, Yilgor E, Erman B. Electrospinning of polyurethane fibers. 2002;43:3303-3309.

38. Mo XM, Xu CY, Kotaki M, Ramakrishna S. Electrospun P(LLA-CL) nanofiber: a biomimetic extracellular matrix for smooth muscle cell and endothelial cell proliferation. Biomaterials. 2004;25(10):1883-1890.

39. Kim KD, Kim HT. Formation of Silica Nanoparticles by Hydrolysis of TEOS Using a Mixed Semi-Batch / Batch Method. Journal of Sol-Gel Science and Technology. 2002;25:183-189.

40. Schmidt H. Chemistry of material preparation by the sol-gel process. Journal of NonCrystalline Solids. 1988;100:51-64.

41. Brinker CJ, Scherer GW. Sol-gel science, the physics and chemistry of sol-gel processing.; 1990. 
Figure legends:

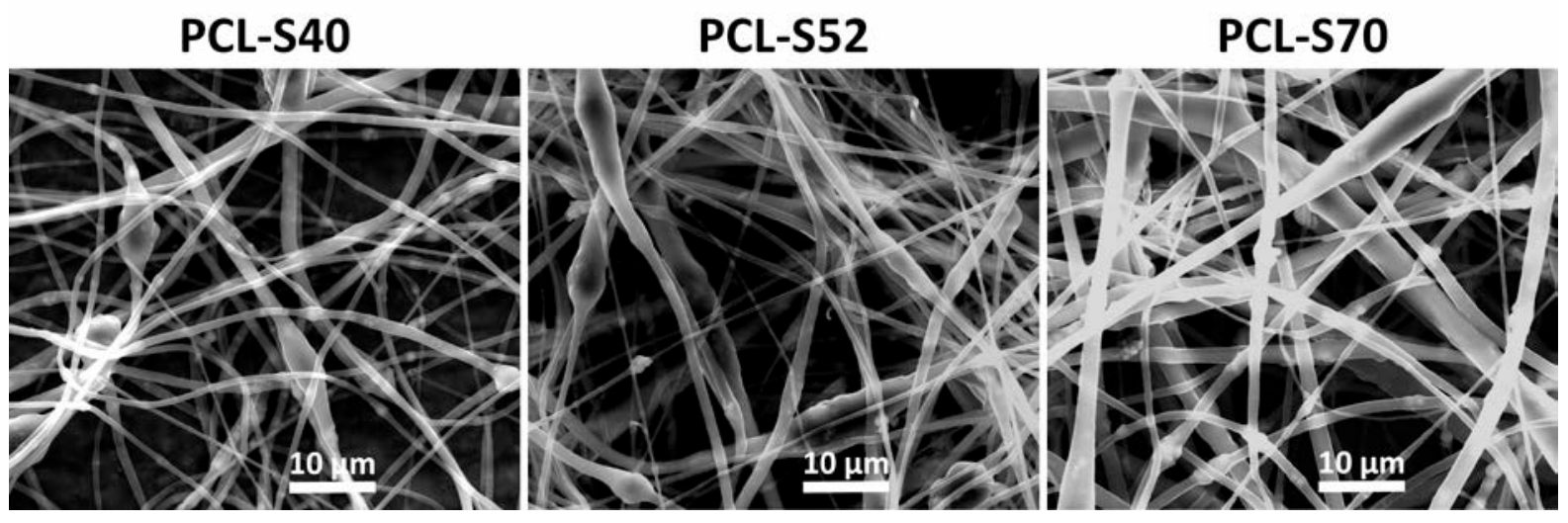

Figure 1 Morphology of the hybrid fibers prepared with different ormoglass compositions and THF as solvent (SEM images) 

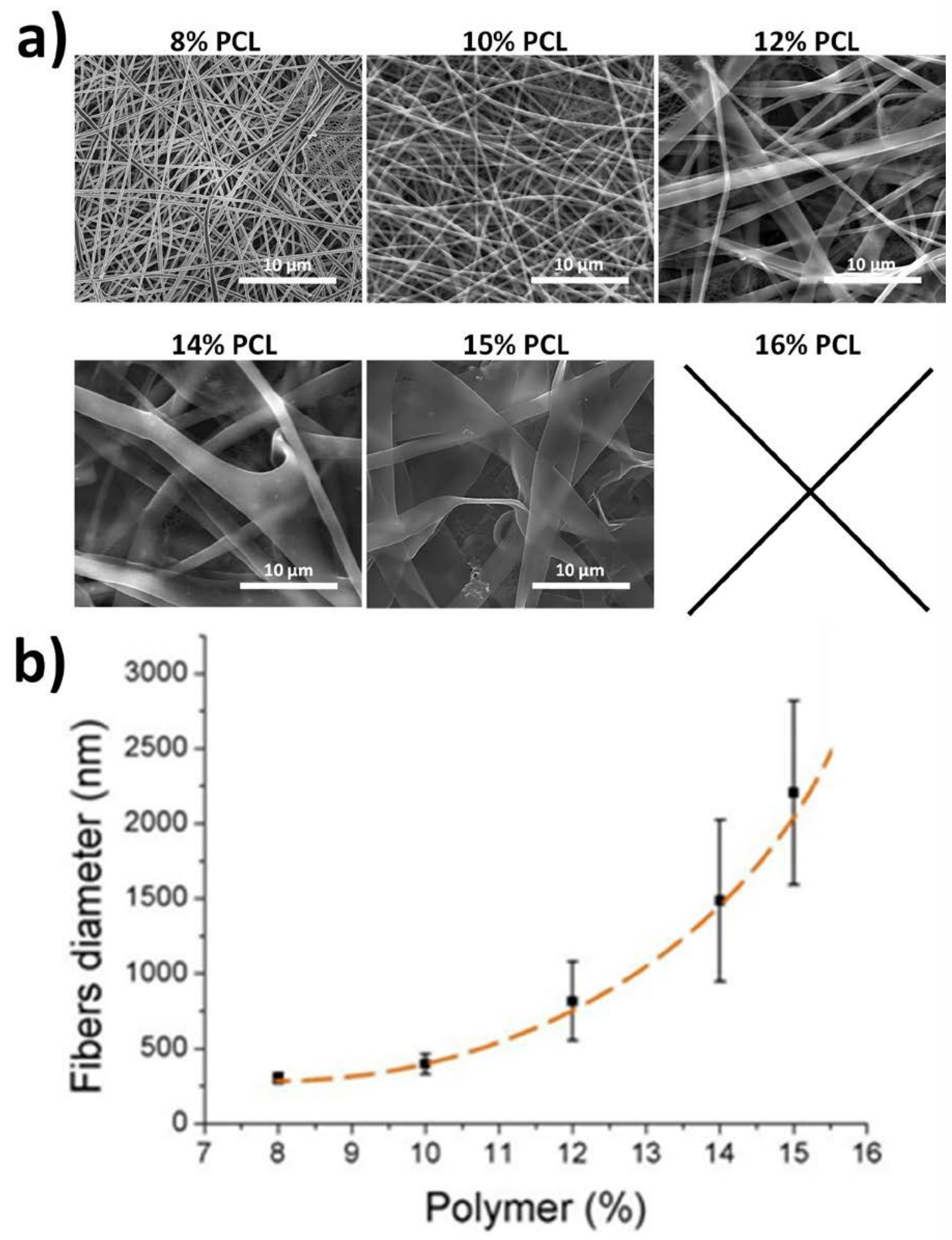

Figure 2 Influence of polymer concentration on hybrid PCL-S52 fibers. a) Morphology

(SEM images) and b) thickness of the hybrid fibers (S52 ormoglass composition) obtained with different polymer concentrations and TFE as solvent. 


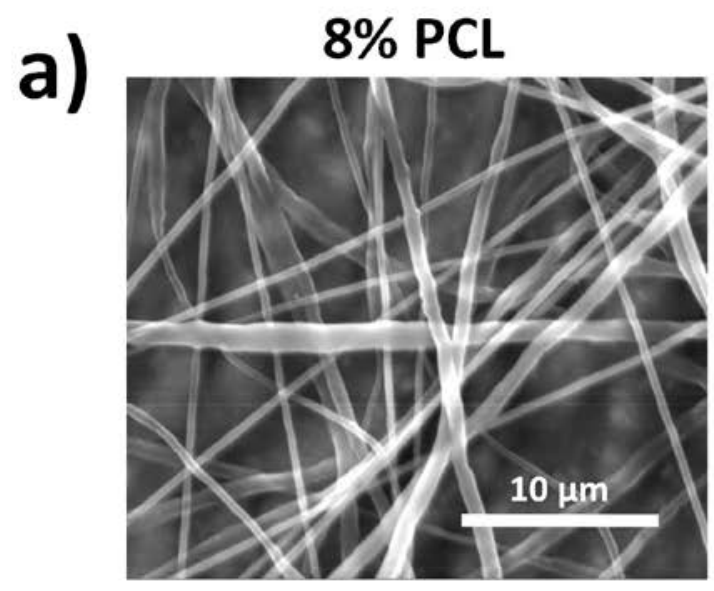

$12 \% \mathrm{PCL}$

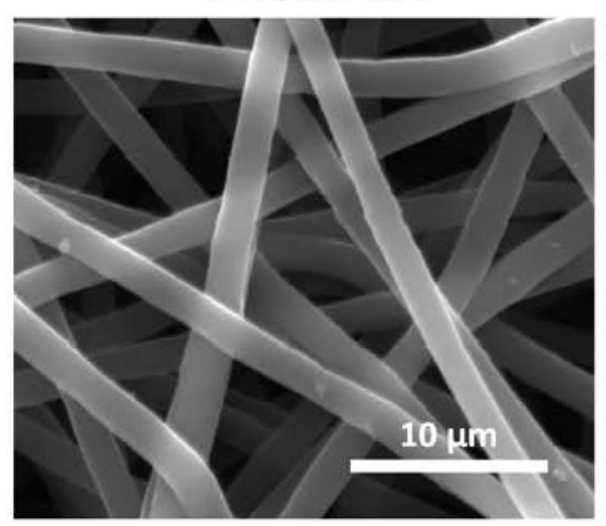

b)

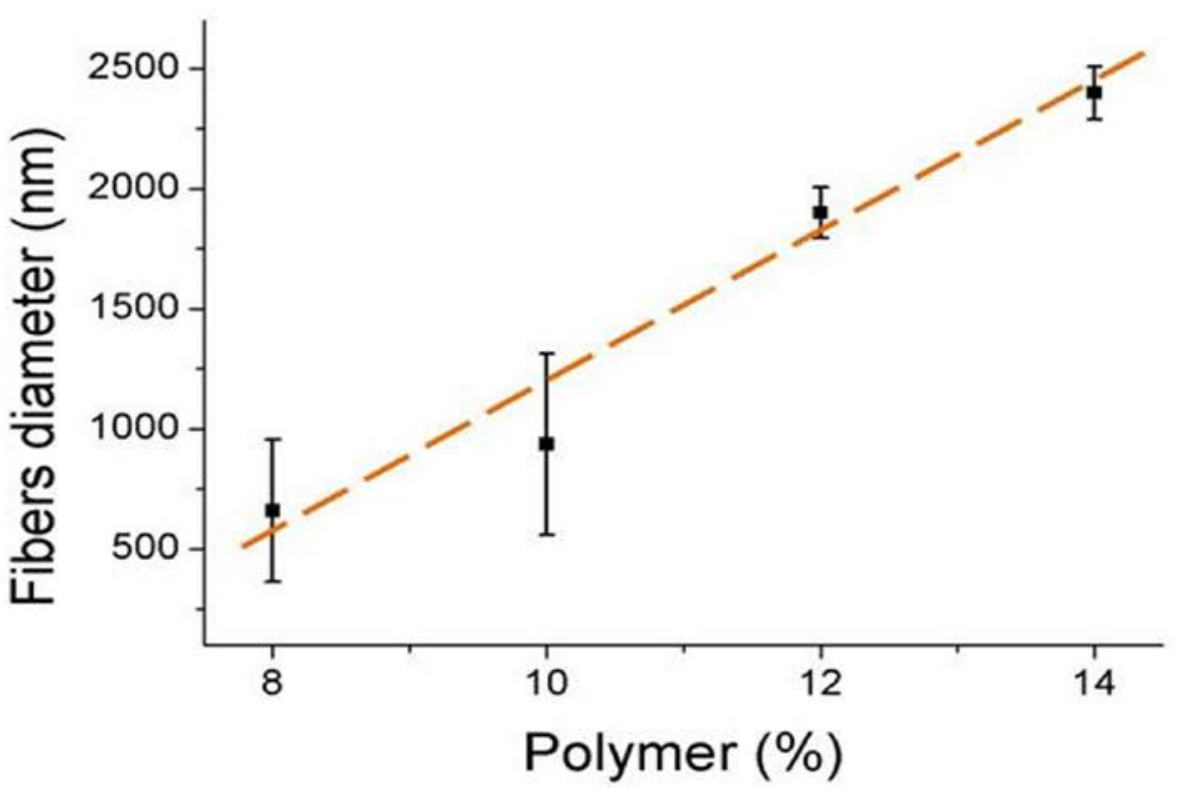

Figure 3 Influence of polymer concentration on pure PCL fibers. a) Morphology (SEM images) and b) thickness of pure PCL fibers obtained with different polymer concentrations and TFE as solvent. 

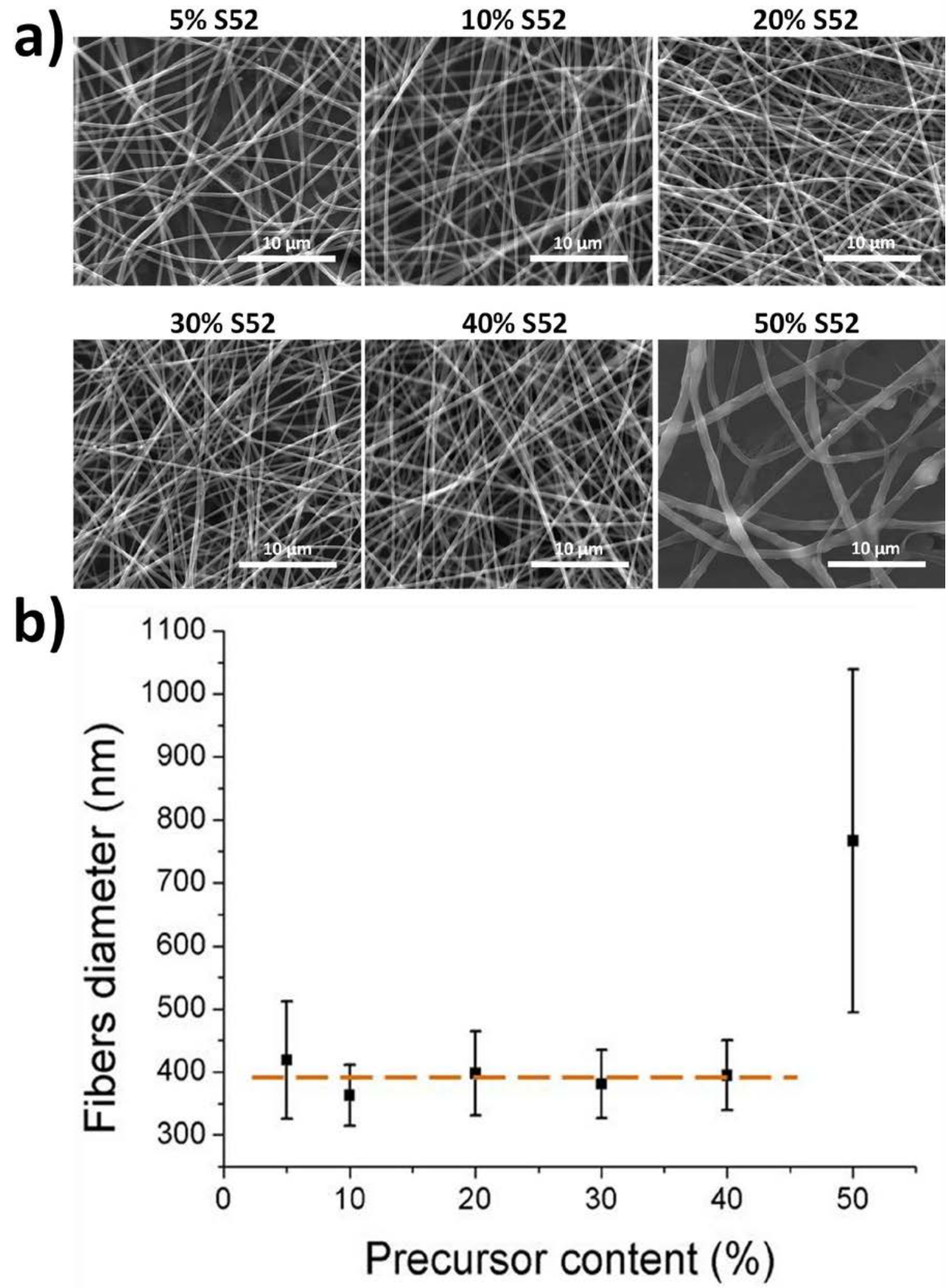

Figure 4 Influence of ormoglass content on hybrid S52 fibers. a) Morphology (SEM images) and b) thickness of hybrid fibers (S52) obtained with different ormoglass contents and with TFE as solvent. 

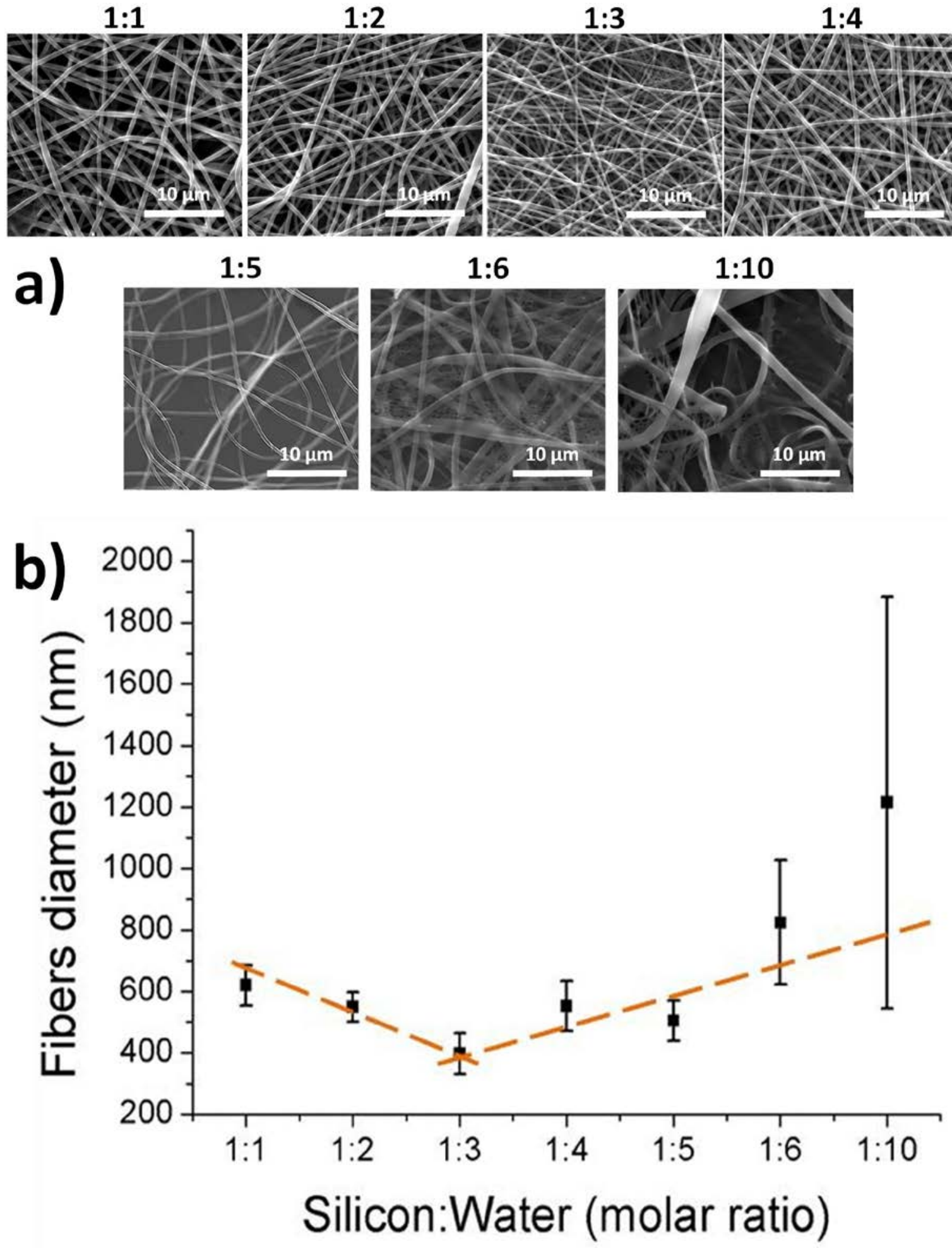

Figure 5 Influence of ormoglass hydrolysis level on hybrid S52 fibers. a) Morphology (SEM images) and b) thickness of hybrid fibers (S52) obtained with different ormoglass hydrolysis ratios and TFE as solvent. 


\section{Table captions:}

Table 1 Label and molar composition of the precursor mix used to prepare the hybrid fibers.

Table 2 Summary of the different solutions parameters considered to produce the hybrid fibers.

Table 3 Thickness of the hybrid fibers prepared with different ormoglass compositions and THF as solvent.

Table 1

\begin{tabular}{|c|c|}
\hline Label of precursor mix & Si:Ca:P $\mathbf{P}_{2}$ molar ratio \\
\hline S40 & $40: 50: 10$ \\
\hline S52 & $52: 40: 8$ \\
\hline S70 & $70: 25: 5$ \\
\hline
\end{tabular}


Table 2

\begin{tabular}{|c|c|c|c|c|c|}
\hline & $\begin{array}{c}\text { Ormoglass } \\
\text { Composition }\end{array}$ & Solvent & $\begin{array}{c}\text { Polymer } \\
\text { concentration } \\
\text { (\% w/w } \\
\text { ratio) }\end{array}$ & $\begin{array}{c}\text { Ormoglass } \\
\text { Content } \\
\text { (\% v/v } \\
\text { ratio) }\end{array}$ & $\begin{array}{c}\text { Si: } \mathbf{H}_{2} \mathbf{O} \\
\text { molar } \\
\text { ratio }\end{array}$ \\
\hline $\begin{array}{c}\text { Fibers } \\
\text { (control) }\end{array}$ & $\begin{array}{l}\text { S70 } \\
\text { S52 } \\
\text { S40 }\end{array}$ & THF & 16 & 20 & $1: 3$ \\
\hline $\begin{array}{c}\text { Influence of } \\
\text { polymer } \\
\text { concentration }\end{array}$ & S52 & TFE & $\begin{array}{c}8,10,12,14 \\
15,16\end{array}$ & 20 & $1: 3$ \\
\hline $\begin{array}{c}\text { Influence of } \\
\text { ormoglass } \\
\text { content }\end{array}$ & S52 & TFE & 10 & $\begin{array}{l}5,10,20, \\
30,40,50\end{array}$ & $1: 3$ \\
\hline $\begin{array}{l}\text { Influence of } \\
\text { hydrolysis } \\
\text { molar ratio }\end{array}$ & S52 & TFE & 10 & 20 & $\begin{array}{c}1: 1,1: 2, \\
1: 3,1: 4, \\
1: 5,1: 6, \\
1: 10\end{array}$ \\
\hline
\end{tabular}


Table 3

\begin{tabular}{|c|c|c|}
\hline $\begin{array}{c}\text { Label of the hybrid } \\
\text { fibers }\end{array}$ & $\begin{array}{c}\text { Composition } \\
\text { (Si:Ca:P } \mathbf{P}_{\mathbf{2}} \text { molar } \\
\text { ratio) }\end{array}$ & Diameter \\
& $(\boldsymbol{\mu m})$ \\
\hline PCL-S40 & $40: 50: 10$ & $1.409 \pm 0.417$ \\
\hline PCL-S52 & $52: 40: 8$ & $1.418 \pm 0.555$ \\
\hline PCL-S70 & $70: 25: 5$ & $1.505 \pm 0.326$ \\
\hline
\end{tabular}

